\title{
Para lá das religiões: pressupostos epistemológicos e ético-antropológicos para um ethos global
}

João Maria André

\section{OpenEdition}

\section{Journals}

Edição electrónica

URL: http://journals.openedition.org/rccs/1578

DOI: $10.4000 /$ rccs. 1578

ISSN: 2182-7435

Editora

Centro de Estudos Sociais da Universidade de Coimbra

\section{Edição impressa}

Data de publição: 1 setembro 2011

Paginação: 109-117

ISSN: 0254-1106

\section{Refêrencia eletrónica}

João Maria André, «Para lá das religiões: pressupostos epistemológicos e ético-antropológicos para um ethos global », Revista Crítica de Ciências Sociais [Online], 94 | 2011, posto online no dia 01 outubro 2012, consultado o 22 setembro 2020. URL : http://journals.openedition.org/rccs/1578 ; DOI : https:// doi.org/10.4000/rccs. 1578 


\title{
Revisões Críticas
}

\section{Para lá das religiões: pressupostos epistemológicos e ético-antropológicos para um ethos global}

\author{
Revisão de Magalhães, Isabel Allegro de (2011), Para lá das religiões. Ensaios sobre \\ religiões e culturas, ética, espiritualidade, política. Lisboa: Chiado Editora, 491 pp.
}

Isabel Allegro de Magalhães propõe-nos um livro, que reúne 18 textos produzidos em ocasiões diversas e sob vários pretextos, subordinando-os ao título Para lá das religiões. O livro apresenta-se dividido em três partes: "Para lá das Religiões", "Presença ao mundo" e "Subversão e solicitude", sendo completado por uma extensa bibliografia que permite identificar as principais referências teóricas da autora.

A primeira secção, embora sob o título "Para lá das religiões" é, fundamentalmente, nos cinco ensaios que a integram, uma reflexão sobre o religioso que atravessa as múltiplas experiências do ser humano: a experiência artística e literária (o primeiro ensaio faz um rastreio do divino em vultos representativos das letras portuguesas), a experiência feminina do transcendente e a especificidade da sua tradução em linguagem (o segundo ensaio é um percurso pela epistemologia subjacente às teologias feministas), a experiência do lugar de fronteira e tantas vezes de ruptura que o profético e o místico encarnam na sua inscrição numa religião situada no espaço e no tempo (o terceiro ensaio, tomando como pretexto uma homenagem a Frei Bento Domingues, procura reflectir sobre essa dupla condição do ser religioso: alguém que está no mundo, mas simultaneamente em ruptura com o mundo e com as instituições em que se consubstancia social e historicamente essa presença no mundo), a experiência da espiritualidade que é própria do cristianismo, mas que atravessa igualmente todas as outras religiões com as quais a autora dialoga (o quarto ensaio desta secção, intitulado "uma atenção absoluta" é, simultaneamente, uma fenomenologia de uma atenção do absoluto e ao absoluto na espiritualidade religiosa, mas que se estende pela espiritualidade artística e literária) e, finalmente, a experiência da liberdade, tal como esta se vivencia na radicalidade do encontro com Deus e na responsabilidade decorrente desse mesmo encontro na sua expressão celebrativa e litúrgica e também praxística e ética (o último ensaio desta secção, intitulado "a vertical do lugar", aprofunda as zonas do exercício da liberdade a partir do lugar religioso e do modo como a sua vertical impregna a presença humana na interacção com os outros). A segunda secção, intitulada "Presença ao mundo", opera uma inscrição do "Para lá das religiões" no mundo e perante o mundo com e em que se faz a nossa existência quotidiana. O objectivo é mostrar como a experiência religiosa se inscreve criticamente e activamente no mundo, de uma forma militante, com o objectivo de transformar esse mesmo mundo. O primeiro ensaio desta secção constitui a chave de todos os outros e da própria posição da autora: retoma um motivo recorrente nos textos do teólogo Hans Küng, a necessidade da construção de uma ética global, e, sob o título "Um ethos global: contributo das religiões", procura explicitar um conjunto de traços comuns a todas as 
religiões que poderiam configurar os valores fundamentais presentes em todas elas e considerados indispensáveis para que a humanidade se salve e salve simultaneamente o seu futuro. O segundo ensaio desta secção, intitulado "Monoteísmo(s) e fundamentalismo(s)", interroga a problemática dos fundamentalismos nas sociedades actuais, questionando o vínculo que alguns pretendem ver entre religiões monoteístas e tentações fundamentalistas e mostrando como no coração das religiões abraâmicas se inscreve sempre uma tensão entre identidade e alteridade, entre unidade e multiplicidade, entre violência e tolerância, entre uma apologética da conversão e um respeito dialógico pela diferença. O terceiro ensaio parte do impacto dos cartoons do profeta Maomé publicados na Dinamarca, para recolocar o debate e o problema que a publicação desses mesmos cartoons suscita, não tanto no plano da liberdade de imprensa, como foi habitualmente colocado, mas no plano da ética e, mais especificamente, da responsabilidade que o relacionamento com o outro, como outro e como diferente, suscita numa sociedade multicultural e plurirreligiosa como é aquela em que vivemos, com a consequente relativização do ethos europeu que tende a absolutizar-se e a universalizar-se como se fosse o único ethos possível para toda a humanidade. O quarto ensaio desta secção constitui a fundamentação do título da própria secção: intitulado "Presença ao mundo", é uma incursão por dois dos principais textos do Concílio Vaticano II, a constituição Gaudium et spes e a constituição Lumen gentium, para mostrar como a espiritualidade religiosa e cristã se tece não a partir de uma ignorância ou de um alheamento do mundo, mas precisamente com base numa inscrição no tempo e nos tempos, no mundo e nos mundos, na história e nas histórias dos homens, sejam eles crentes ou não, pois é aos homens de boa vontade que a mensagem cristã se dirige e não apenas àqueles que expressamente professem o credo do cristianismo. Surge depois um novo ensaio, intitulado "O limiar como lugar”, que apela a uma descentração e a uma desterritorialização da igreja dos seus lugares tradicionais, mais ou menos ortodoxos, como centro da verdade, da revelação e dos valores, para a inscrever num espaço de limiar em que se abre ao mundo, à pluralidade de culturas e ao que é diferente de si própria, mas eventualmente convergente com o sentido mais profundo da sua missão em prol do humano. O sexto ensaio, "Uma outra consciência", prolonga os caminhos abertos no primeiro ensaio desta secção, pesquisando a forma como, numa sociedade globalizada e marcada pelas injustiças de um neoliberalismo predador e economicamente perverso, a presença intersticial do religioso pode contribuir para um novo ethos global centrado na responsabilidade pelo próximo, na intervenção comprometida, no amor exercido também como perdão e na confiança na energia do mundo e da sua alegria. Esta secção encerra com um manifesto-festa da esquerda, que aponta para uma política celebrativa do cuidado e da esperança na qual se podem unir crentes e não-crentes em ordem a uma "despoluição da democracia” e à construção de uma cidadania mais justa e solidária.

A terceira e última secção, intitulada "Subversão e solicitude", respiga alguns exemplos de pessoas ou obras que são testemunhas de como, para lá das religiões, mas profundamente enraizadas na mensagem que transportam, é possível estar presente ao mundo e no mundo, estabelecendo a fé como espaço de limiar e de abertura para as preocupações das pessoas, do tempo e da história. Os dois primeiros ensaios são dedicados a Maria de Lurdes Pintasilgo e à forma como soube fazer $\mathrm{da}$ 
sua vida um lugar de articulação entre fé e política e fazer do espaço público um lugar de concretização de uma ética do cuidado, que se inscreve no presente sem abandonar o futuro e se inscreve no futuro sem desertar dos desafios que o presente nos lança. $\mathrm{O}$ terceiro ensaio inscreve mais uma vez a problemática do género no discurso religioso, ao sintetizar o contributo que várias mulheres elaboraram num livro publicado sob a coordenação de Manuela Silva sobre "os textos da Fé na leitura das mulheres". O quarto ensaio toma também como referência um livro de Manuela Silva, em que a autora reúne um extenso conjunto de textos que documentam a sua atitude de escuta do vento e para lá do vento: escuta dos sinais dos tempos, escuta dos testemunhos de presença ao mundo, escuta das necessidades mais prementes dos seres humanos, sempre em ordem a uma mudança de consciência, a uma conversão do coração, a uma abertura ao Espírito de Deus, seja qual for o nome com que as mulheres e os homens o nomeiam e o vivenciam. Vem depois um ensaio que se adentra na obra de Natália Correia, pesquisando nela vestígios das inquietações que o bíblico, o religioso ou o divino foram deixando nos seus versos, fazendo da sua poética uma poética mística, ainda que agnóstica, e uma poética religiosa, ainda que pagã. Encerra esta secção e este livro um ensaio sobre uma grande religiosa do século quinze, Teresa de Ávila, em que a autora procura as principais categorias a partir das quais pode ser equacionada a sua experiência mística de descentração, deslocalização e desterritorialização e, simultaneamente, a sua experiência de mulher e de pensadora, num século predominantemente marcado pelo discurso religioso no masculino.

Apresentada esta breve síntese do conjunto de ensaios que constituem a obra, gostaria agora de passar a uma leitura mais transversal dos textos, de modo a captar as principais linhas de força que os atravessam e que fazem pressentir neles a génese e um desenvolvimento de um pensamento tão original quanto interventivo e consistentemente formulado.

Começaria por conceder uma atenção especial ao título: "Para lá das religiões". O que procura Isabel Allegro "para lá das religiões"? Procura aquilo que as une na sua diversidade, aquilo que as atravessa na sua especificidade e também aquilo a que se pode chegar mesmo sem partir de um chão estritamente religioso. Nesse contexto, a tentativa de delineamento de um ethos global que atravessa, sobretudo, alguns dos textos da segunda secção constitui um dos principais objectivos e uma das principais preocupações da autora. Eé por esse ethos se encontrar nas religiões, mas, simultaneamente, para além delas, que ele pode constituir uma boa plataforma não só para um fecundo diálogo inter-religioso, mas também para um fecundo diálogo intercultural. Desse ethos partilharão os espíritos estritamente religiosos e motivados essencialmente pelo conteúdo conceptual das suas próprias crenças no qual encontrarão a respectiva fundamentação teórica; mas dele partilharão também os espíritos não religiosos que descobrem no bumanum, na sua dignidade e nos seus valores a inspiração para uma prática convergente com aquela que torna presentes ao mundo os discípulos das diferentes religiões.

Gostaria, em segundo lugar, de explicitar as duas principais tensões que atravessam todos os textos aqui reunidos e que exprimem as duas polaridades com que a própria autora se faz presente no mundo e ao mundo e também na escrita e à escrita como forma de intervenção nesse mesmo mundo. A primeira dessas tensões é a tensão entre a dimensão mística da religião e a sua dimensão activa e interventiva na história, ou seja, a tensão entre a contemplação e a acção. Por um lado, o seu 
cristianismo assenta numa visão de Deus como Deus absconditus, como inefável, suscitando, com isso, uma imersão na união afectiva com ele, no silêncio da contemplação, numa atitude apofática sobre o completamente outro e o absolutamente transcendente ao mundo. Mas, por outro lado, esse mesmo cristianismo comporta uma componente que o enraíza no tempo e na história, no século e na imanência, e que se exprime em princípios éticos que reclamam uma atenção aos outros em que o rosto do completamente Outro se revela e presentifica e que exigem um cuidado com o mundo como espaço de manifestação do sagrado e com o humano como figura da sua encarnação pessoal e concreta. Mas longe de esta tensão corresponder a uma contradição, ela traduz fundamentalmente uma complementaridade: é pelo facto de o "para lá das religiões" ser o mistério que ele se abre a múltiplas formas de expressão e de experiência, que nunca o esgotam mas sempre lhe correspondem como caminhos de que a dimensão ético-praxística é uma vertente incontornável. Não deixa de ser curioso, a este propósito, registar a forma como a autora define a dimensão mística: "uma experienciação do mundo como inscrição da Presença Divina e, ao mesmo tempo, de ligação ao Mistério de Deus, onde 'o mundo está sempre a florescer'" (p. 105). Diríamos que a Isabel Allegro que escreve o livro Para lá das religiões é, verdadeiramente, uma mística, mas uma mística com os pés bem assentes na terra e nas preocupações dos homens e das mulheres que a rodeiam. A segunda dessas tensões é a tensão entre a igualdade e a diferença que encontra diversas concretizações ao longo dos textos. A unidade e a pluralidade das religiões é uma das expressões dessa tensão. Privilegiando a unidade regista-se uma certa tendência a reconhecer a sua igualdade e é a partir dessa igualdade que é possível esboçar um ethos global que se fundamenta nos princípios teóricos que sustêm as principais crenças e que a regra de ouro, já presente em Confúcio mas retomada de diversos modos por cada uma das religiões, tão bem exprime e que Isabel Allegro aprofunda na página 184 da sua obra, tanto na sua versão negativa "não faças nunca ao outro o que não queres que te façam a ti”, como na sua versão positiva "faz sempre aos outros o que queres que te façam a ti”. Privilegiando a diferença das religiões umas em relação às outras, abre-se a porta a uma certa irredutibilidade de cada religião, mas também à possibilidade do encontro e do debate fecundo entre elas. Mas não é apenas ao nível das religiões que se manifesta esta tensão. Ela manifesta-se também na dupla forma ou manifestação do ser humano, o masculino e o feminino. Pode aqui privilegiar-se igualmente a igualdade, acentuando o humano para lá das diferenças de género e de sexo (e é nesse contexto que uma ética para toda a humanidade pode ser formulada), como pode privilegiar-se a diferença, acentuando, por exemplo, a especificidade do feminino na relação com o mundo e com os outros, na relação com o mistério e com o transcendente (como o ensaio "Dizer o indizível: o saber feminino de um não-saber" procura aprofundar) e na relação com os textos bíblicos e com a tradição. Como refere a autora (p. 63) "ao discurso à volta do Divino as teologias feministas poderão trazer uma nova respiração, se procurarem evitar posições simétricas às que dominavam os discursos de muitos dos homens teólogos" acrescentando que "isso só acontece se na sua própria voz enunciarem outras possibilidades da linguagem e do silêncio por dentro dela, sem reactivarem, mesmo numa outra clave, a língua 'homem'”. Não deixa de ser curioso, no entanto, sublinhar que alguns dos autores mais expressivos desta epistemologia negativa inspiradora do discurso feminista 
foram homens e místicos, como é o caso de Mestre Eckhart, Nicolau de Cusa ou João da Cruz. De igualdade e de diferença se faz, segundo Isabel Allegro, a participação cívica de homens e mulheres tanto na coisa pública como na intimidade de uma espiritualidade vivida em comunidade.

Em terceiro lugar, parece importante deter-me em algumas das categorias conceptuais com que se constrói este "para lá das religiões” de que nos fala o título. Algumas dessas categorias são de natureza epistemológica e outras de natureza ético-antropológica.

De entre as categorias epistemológicas salientaria, primeiro, a importância do mistério como fonte das mais diversificadas expressões religiosas e artísticas do ser humano. Esse Mistério é uma claridade que está para além de todas as claridades, tendo sido a atracção por ela que, como é referido na página 13, "originou múltiplas modalidades de religiosidade, a religarem o ser individual e colectivo ao Transcendente. De que as culturas, as artes e as várias áreas de pensamento dão sinal, tal como, embora com outras características e intensidades, dão sinal teologias, experiências místicas, liturgias e cultos, dirigidos ao Mistério desconhecido ou só escassamente apercebido". Deste primado do Mistério resulta a segunda categoria, a da epistemologia negativa (expressão a que a autora recorre, na página 15 , para caracterizar o discurso feminista sobre o divino), e que caracteriza a forma do saber que pretende abordar o Absoluto e o Transcendente, indizível na sua natureza escondida e ao qual só uma "douta ignorância” como aquela que é tematizada por Nicolau de Cusa pode corresponder. Esta epistemologia negativa perante o inefável é complementada por uma epistemologia da escuta, que reclama o silêncio como momento fundamental para a constituição do discurso e que assenta na capacidade de ouvir "o que por dentro da matéria ressoa, no interior da Terra e de cada pessoa, para que tudo venha a convergir num centro a vir" (p. 122), ou seja, que assenta na capacidade de ouvir do vento o que o vento nos diz dos homens, como presença que passa como passa o próprio vento, como nos é referido a propósito do título da obra de Manuela Silva (p. 379 ss.). Em quarto lugar, exactamente por ser negativa, a epistemologia adequada a esta relação com a verdade entendida como mistério deve também ser entendida como uma epistemologia crítica, conjectural e perspectivística, que é naturalmente marcada pela relatividade do olhar de cada um e pela relatividade da sua percepção do mundo e do que se intui para além dele. Por esse motivo, afirma Isabel Allegro, na página 195 do seu livro, que "a questão antropológica e filosófica subjacente é a de que ninguém possui a verdade toda, mas apenas a sua própria perspectiva da verdade, isto é, uma parcela dela", concluindo assim que "a verdade é sempre relativa a um contexto específico, por cada um ter a sua visão própria, sendo que o perspectivismo origina necessariamente a pluralidade”. Em quinto lugar, uma epistemologia perspectivística, que respeita a pluralidade de visões do mundo e de elaborações conceptuais daí decorrentes, é uma epistemologia que se exerce num movimento amplificante da diversidade de culturas através do diálogo intercultural e da diversidade de religiões através do diálogo inter-religioso. Este movimento amplificante é, em termos práticos, um movimento que acaba por ser enriquecedor das identidades próprias, uma vez que "a possibilidade de integrar outras vozes no discurso da identidade nacional permite que cada cultura se amplifique, complexificando-se, em vez de esmagar ou deixar que a sua seja esmagada pela cultura dominante ou diluída numa indistinta mistura cultural” (p. 232). 
Três outros traços completam ainda esta epistemologia negativa, perspectivística e conjectural. Por um lado, para que se possa concretizar, ela começa sempre por ser uma epistemologia do espanto, ou seja, corresponde a uma atitude em que a capacidade de se admirar perante o outro é o ponto de partida para o encontro com o outro, seja ele aquele que nos está próximo, seja o fundo do mistério que nos ultrapassa e que ultrapassa a nossa linguagem. É essa uma das lições que Isabel Allegro retira da experiência mística de Teresa de Jesus que, como é referido, "mostra viver o saber de um não-saber que nela suscita espanto ou um pasmo essencial" (p. 433). Por outro lado, essa epistemologia negativa e perspectivística realiza-se necessariamente como uma epistemologia dialógica ou dialogal, que transforma o respeito em interacção e o espanto em complementaridade. Esse diálogo, para o crente, deve começar precisamente através da relação entre fé e cultura no processo de inculturação da fé, que "significa a sua inserção, incorporada, nas culturas e nas linguagens específicas de cada local" (p. 254) e deve prolongar-se depois através de um diálogo intercultural e inter-religioso que a disponibilidade para o acolhimento do outro acentua e proporciona. Finalmente, e por último, essa epistemologia negativa, perspectivística e dialógica concretiza-se discursivamente numa epistemologia metafórica ou icónica, que assume a polissemia simbólica da metáfora como caminho para exprimir, de uma forma mais adequada, o fundo misterioso do ser e da vida. No símbolo e no ícone, "é o mistério que faz apelo" (p. 97) e é por isso que o discurso que emerge de uma epistemologia icónica não é um discurso representativista, mas uma forma de dizer que se situa entre o visível e o invisível, sem reduzir este último às suas manifestações. Compreende-se, pois, que Isabel Allegro, inspirada por esta epistemologia metafórica e icónica, encontre na arte, especialmente na poesia, um campo privilegiado para a investigação dos sinais divinos e transcendentes no discurso humano, como o exemplificam as suas incursões realizadas no primeiro capítulo, em que articula "mundos, artes e religiões", e no capítulo sobre Natália Correia cuja poética parece caracterizar-se simultaneamente como pagã, panteísta e mística, ostentando uma espiritualidade que é, ao mesmo tempo, literária, cultual e litúrgica. A última nota, da natureza epistemológica, que gostaria de sublinhar como subjacente a estes ensaios de Isabel Allegro diz respeito à assunção de uma epistemologia da fronteira e do limiar, ou seja, uma epistemologia que constrói o seu saber a partir de um lugar que se sabe não o centro privilegiado do mundo ou do conhecimento, mas uma periferia que marca uma relação itinerante com a verdade, a qual, aplicada à Igreja, pressupõe simultaneamente uma Igreja do limiar e da fronteira, para utilizar a expressão de Yves Congar, referência permanente da autora, que se coloca em posição de olhar e ouvir o que é diferente de si.

Partindo destas premissas epistemológicas é-nos agora possível explicitar alguns traços ético-antropológicos que marcam a reflexão e as abordagens de Isabel Allegro. Assim, o primeiro traço, de natureza antropológica, a que gostaria de fazer referência é uma concepção descentrada do ser humano em relação a si próprio, afirmada logo no início do primeiro ensaio de modo bastante incisivo: cada um deve entender-se a si mesmo "como ser descentrado com o cerne do sentido fora de si" (p. 15). É essa condição de ser descentrado que faz do homem essencialmente uma procura "quer na elevação do ser humano à sua qualidade maior, quer na relação ao outro de si (os outros, a natureza, o mundo, a história, o cosmos), quer 
na realização de si na interioridade da contemplação, no silêncio e na palavra, na criatividade e no despojamento, na inquietação e na generosidade" (p. 117). Esta descentração resulta da finitude, como "traço essencial do ser humano" (p. 165), e repercute-se numa permanente despossessão interior e exterior do homem em relação a si próprio, reclamando virtudes éticas como o não-egoísmo, a rectidão e o sentido da compaixão e da harmonia (p. 173). Este traço antropológico assenta, ontologicamente, num reconhecimento do fundo e fundamento do ser como Mistério e Invisível, tenha ele o nome de Deus, como nas religiões, ou outro nome mais filosófico ou simbólico, que a linguagem metafórica e poética tantas vezes procura exprimir na sua indizibilidade (p. 65) e que funda o misticismo como forma de estar no mundo sem se perder nele. Tal indizível não nos é acessível directamente, mas só através de mediações cujos lugares são, na opinião da autora, "a Terra, o Cosmos, o Mundo, o corpo e o coração de cada um" (p. 74) e é a partir desses lugares que se vai à procura do que nos transcende. Ora tais mediações são, por natureza, históricas e é por esse motivo que, mesmo as religiões, na sua busca do Transcendente e do Absoluto, não podem esquecer que é historicamente que é acolhida a Revelação pelo homem e que essa historicidade marca com a incompletude a sua apropriação humana, cujo reconhecimento é indispensável para responder às tentações de dogmatismo e fundamentalismo que tantas vezes assaltam o homem religioso. Do primeiro traço da descentração e do segundo referente à presença do mistério e à historicidade das suas mediações resulta, em terceiro lugar, uma concepção da consciência como algo não estático, mas em permanente devir, ou seja, uma consciência que evolui, que vive num devir de si mesma" e que, por isso, "supõe inteira liberdade quanto às seguranças adquiridas” (p. 143). E se a consciência está em devir, também o está a moral, sendo este o quarto traço ético-antropológico subjacente às propostas da autora. "A moral”, diz Isabel Allegro, "tem de ser equacionada num quadro que está em permanente devir, sem cedência a facilidades sem critério e sem intransigências normativas" (p. 274). Pressupõe-se, assim, que o dinamismo que caracteriza o ser humano, caracteriza também a sua consciência ética e é sobre ele que terá de ser elevada uma moral para o presente e para o futuro. Sobre estes quatro traços se apoia então o delineamento de uma ética baseada num ethos global que possa abrir o caminho para uma relação mais harmoniosa e equilibrada dos homens entre si e dos homens com o mundo e com a natureza. Algumas características vão, ao longo dos textos, sendo apresentadas para definir e precisar essa ética global. Em primeiro lugar, é recorrentemente referido que ela deve ser uma ética dialógica da responsividade e da responsabilidade: tal ética é uma ética que se traduz "no acto de dar resposta a si mesmo e aos outros" (p. 134), de "participar no que nos vem ao encontro" (p. 135), de responder "ao rosto do outro que nos obriga” (evocação de Levinas na página 226) e de responder também pelo curso da História, através das pequenas responsabilidades que somos convidados a assumir quotidianamente, como a responsabilidade "pela família, pela nossa comunidade de vida, por relações próximas [...], pelo que nos rodeia, escolhido ou não, mas que constitui parte integrante do tecido de cada vida” (p. 293). Em segundo lugar, por ser uma ética da responsabilidade, ela deve ser, por essência, uma ética da liberdade, de que a autora procura caracterizar as respectivas zonas assim enumeradas: responsividade e responsabilidade, 
consciência unitiva, gesto litúrgico, consciência em devir, distanciamento interior, transfiguração da memória e não-escolha do rosto para amar (pp. 133-149). Em terceiro lugar, essa ética tem de ser uma ética da alteridade, contrariando a preferência pelo idêntico conatural ao ser humano. Essa ética da alteridade tanto nos abre horizontalmente para os outros de nós próprios no plano social, cultural e religioso, como nos pode abrir verticalmente para o absolutamente Outro, raiz de toda a religiosidade e de toda a relação ao divino. Em quarto lugar, essa ética da alteridade desemboca naturalmente numa ética do amor, sendo o amor uma das constantes de todas as religiões, que a "regra de ouro" já formulada por Confúcio mas assumida por todos os credos tão bem traduz (p. 184). Tal ética do amor, como ética da gratuidade total na sua radicalidade, inclui como sua dimensão fundamental o perdão, com a consciência de que "perdoar a alguém não é esquecer o mal feito, mas possibilitar a esse alguém um recomeço" (p. 181), "possibilitar-lhe um futuro" (p. 298), como condição de abertura para "um imenso ágape universal" (p. 272) onde todos poderão conviver em solidariedade e harmonia. Em quinto lugar, essa ética da alteridade prolonga-se numa ética unitiva, numa "consciência em que o fragmentado e desmembrado real se reúne por um movimento interior que unifica o ser diante do Mistério" (p. 137), reforçando assim a dimensão ontológica desta ética enraizada na existência. Em sexto lugar, surge a dimensão da justiça como sua característica fundamental: uma justiça que implica, nas palavras de Isaías citadas na página 76, "quebrar todos os jugos, libertar os oprimidos, partilhar o teu pão com quem tem fome e recolher aqueles que não têm abrigo". Em sétimo lugar, correlativa da justiça e do amor, surge a dimensão do respeito: uma ética da alteridade é, por natureza, uma ética do respeito. É nesse sentido que se afirma que para uma elevação do sentido ético mundial, "é sempre tido como bem o respeito activo perante a alteridade e perante o cosmos" (p. 163), sendo também "a ética do respeito" que permite avaliar a correcção ou não da publicação dos cartoons sobre o profeta Maomé, a partir de um espanto admirativo perante a alteridade que é o contrário do exercício de um poder sobre o outro (pp. 220, $221 \mathrm{e}$ 224). Em oitavo lugar, este ethos global para toda a humanidade tem de assentar também numa ética do cuidado, que é delineada a partir da posição teórica e do comportamento ético e político de Maria de Lurdes Pintasilgo, reconhecendo no cuidar "o cerne da política" (p. 335), como seu "fulcro" (p. 341) ou sua "matriz" (p. 342). É através do cuidado que se pode promover a qualidade de vida a que todos têm direito pela sua humanidade. Mas o cuidado não é apenas em relação ao próximo, nosso semelhante, mas também em relação ao mundo que constitui a nossa casa e que constitui incontornavelmente uma preocupação inscrita no desenho de um ethos global. Finalmente, uma ética da alteridade, do respeito, do amor e do cuidado é também necessariamente uma ética da paz, sendo esse um dos objectivos e uma das preocupações por detrás do diálogo intercultural e do diálogo inter-religioso. Resta acrescentar que é nesta ética que se encontra, a partir das religiões, o "para lá das religiões" e que deve ser a ética a medida da religião e não o inverso como se pode deduzir das palavras de Dalai Lama, citadas na página 112 , ao estabelecerem que a religião que conseguir fazer do ser humano "mais compassivo, sensível, mais desapegado, mais amoroso, mais humanitário e mais responsável" é "a melhor religião". 
Para lá das religiões é um livro escrito por uma pessoa crente, com as suas raízes e o seu horizonte profundamente marcados pelo cristianismo. Mas é, ao mesmo tempo, um livro aberto a todos os homens e mulheres de boa vontade. Pelos pressupostos epistemológicos que o enformam é, essencialmente, um livro de diálogo. E pelos princípios éticos e antropológicos em que se consubstanciam as suas propostas é um livro de encontro entre culturas, religiões, teologias e filosofias, face ao Mistério do Ser perante o qual se cala a nossa pertença ao mundo e o sentido profundo da nossa existência.

João Maria André 